\title{
BMJ Open Opposite trends in the consumption of manufactured and roll-your-own cigarettes in Spain (1991-2020)
}

\author{
Marcela Fu, ${ }^{1,2,3}$ Jose M Martínez-Sánchez, ${ }^{1,2,4,5}$ Ramon Clèries,, 2,3,6 \\ Joan R Villalbí, ${ }^{7,8,9}$ Richard A Daynard, ${ }^{5}$ Gregory N Connolly, ${ }^{10}$ \\ Esteve Fernández ${ }^{1,2,3}$
}

To cite: Fu M, MartínezSánchez JM, Clèries $\mathrm{R}$, et al. Opposite trends in the consumption

of manufactured and rollyour-own cigarettes in Spain (1991-2020). BMJ Open 2014;4:e006552.

doi:10.1136/bmjopen-2014006552

- Prepublication history and additional material is available. To view please visit the journal (http://dx.doi.org/ 10.1136/bmjopen-2014006552).

Received 8 September 2014 Revised 9 October 2014 Accepted 13 November 2014

CrossMark

For numbered affiliations see end of article.

Correspondence to Dr Jose M Martínez-Sánchez; jmmartinez@iconcologia.net

\section{ABSTRACT}

Objective: The aim of this study is to describe trends in the consumption of manufactured and roll-your-own cigarettes between 1991 and 2012 in Spain, and to project these trends up to 2020 .

Methods: We estimated daily consumption per capita during 1991-2012 using data on sales of manufactured cigarettes (20-packs) and rolling tobacco $(\mathrm{kg})$ from the Tobacco Market Commission, and using data of the Spanish adult population from the National Statistics Institute. We considered different weights $(0.5,0.8$ and $1 \mathrm{~g})$ to compute the number of rolled cigarettes per capita. We computed the annual per cent of change and assessed possible changes in trends using joinpoint regression, and projected the consumption up to 2020 using Bayesian methods.

Results: Daily consumption per capita of manufactured cigarettes decreased on average by $3.0 \%$ per year in 1991-2012, from 7.6 to 3.8 units, with three trend changes. However, daily consumption per capita of roll-your-own cigarettes increased on average by $14.1 \%$ per year, from 0.07 to 0.92 units of $0.5 \mathrm{~g}$, with unchanged trends. Together, daily consumption per capita decreased between $2.9 \%$ and $2.5 \%$, depending on the weight of the roll-your-own cigarettes. Projections up to 2020 indicate a decrease of manufactured cigarettes (1.75 units per capita) but an increase of roll-your-own cigarettes (1.25 units per capita).

Conclusions: While the consumption per capita of manufactured cigarettes has decreased in the past years in Spain, the consumption of roll-your-own cigarettes has increased at an annual rate around 14\% over the past years. Whereas a net decrease in cigarette consumption is expected in the future, use of roll-your-own cigarettes will continue to increase.

\section{INTRODUCTION}

Smoking is the leading cause of preventable morbidity and premature mortality worldwide. ${ }^{1}$ As a consequence of the increasing awareness of the population of the harmful effects of smoking and the tobacco control
Strengths and limitations of this study

- Our study allowed us to provide an estimation of tobacco sales (and tobacco consumption) at a national level and, more importantly, allowed us to compare the consumption of manufactured and roll-your-own cigarettes.

- We estimated the cigarette consumption per capita by means of the information available on product sales. This information provides a crude estimation of the population's consumption.

- The proportion of roll-your-own cigarettes from overall cigarettes per capita increased from $0.9 \%$ in 1991 to $19.6 \%$ in 2012.

- Projections indicate a $36 \%$ increasing trend of roll-your-own cigarette consumption per capita by 2020 , representing $41.6 \%$ of overall cigarettes per capita by that year. These projections put into evidence the need of developing urgent measures in order to prevent and control the spread of roll-your-own cigarettes and other alternative forms of tobacco products, especially in vulnerable populations.

policies promoted by the WHO Framework Convention on Tobacco Control, ${ }^{2}$ a decrease in cigarette consumption has been observed in many developed countries in the past years. In Western Europe, cigarette consumption dropped by $26 \%$ between 1990 and $2009 .^{3}$ Nevertheless, the use of forms of tobacco other than conventional cigarettes is becoming widespread, because of their lower regulation and prices. ${ }^{4}$

Although a decreasing conventional manufactured cigarette smoking has been also described in adolescents, ${ }^{5}{ }^{6}$ the concurrent use of multiple tobacco products is becoming prevalent among young populations. ${ }^{7}$ In this sense, the use of rolling tobacco, or roll-your-own (RYO) cigarettes, is increasing in many countries, ${ }^{8}$ in part because of the widespread belief of minimal hazardous health effects. ${ }^{9}$ Evidence does not support 
this belief; on the contrary, rolling tobacco yields higher nicotine, tar and carbon monoxide levels than manufactured cigarettes. ${ }^{10-12}$

As in other countries, the economic crisis during the past years in Spain seems to have led to an increase in the consumption of other tobacco products subject to lower taxes and thus being cheaper for smokers. ${ }^{13}$ The aim of this study is to describe trends in the consumption of manufactured and RYO cigarettes between 1991 and 2012 in Spain, and to project these trends up to 2020.

\section{METHODS}

We used the official Spanish data on annual legal sales of tobacco products from the Tobacco Market Commission. ${ }^{14}$ The Commission collects information on tobacco product sales to smokers from tobacconists. We included data from the Iberian Peninsula \& the Balearic Islands and excluded data from Canary Islands and Ceuta \& Melilla, because of the different taxation rules in these provinces. We considered annual data on manufactured cigarettes and rolling tobacco from 1991, when this latter item was first included in the registries, up to 2012. Information on manufactured cigarettes was first reported in million packs of cigarettes and then in packs of 20 cigarettes. For rolling tobacco, nevertheless, there has been some variability in the way the statement has been made. It was first expressed in millions of packages (from 1991 to 1998), then in millions of bags (from 1999 to 2000), then in millions of bags or cans (from 2001 to 2008), and finally in $\mathrm{kg}$ of product (from 2008 up to now). We assumed that one pack/bag/can of rolling tobacco weighs $50 \mathrm{~g}$, on the basis of the available data in 2008, when the information on sales was available in both bags/cans and in kilograms. ${ }^{15}{ }^{16}$ We estimated this figure by dividing the total grams sold in 2008 by all the bags/cans sold that same year, resulting in $46.85 \mathrm{~g}$. Using the rounded figure of $50 \mathrm{~g}$ per unit of $\mathrm{pack} / \mathrm{bag} / \mathrm{can}$, we were able to estimate the sales of rolling tobacco in $\mathrm{kg}$ of the product for the whole study period (1991-2012).

We also collected data of the Spanish population $\geq 16$ years old for the period 1991-2012, using the population censuses and the official intercensuses data (available up to 2012) from the National Statistics Institute. ${ }^{17}$ This information allowed us to estimate the average number of manufactured and RYO cigarettes per year and person. ${ }^{18}{ }^{19}$ Since this information is public aggregated data and it does not contain data on individuals, ethical approval was not required.

Since the amount of tobacco included in a unit of RYO cigarette is variable as it depends on the way the smoker makes the roll, ${ }^{12}$ we considered three possible weights to estimate the number of cigarettes: $0.5,0.8$ and $1 \mathrm{~g}$ of tobacco. For each option, we calculated the annual per cent of change (APC) of the number of cigarettes per person and year for manufactured cigarettes, RYO cigarettes, and both type of cigarettes taken together.
In order to assess changing trends during 1991-2012, we used joinpoint regression. According to the procedure developed by Kim et $a l^{20}$ and based on the shape of the time trend of the daily cigarette consumption per capita, we assumed a maximum number of four joinpoints. To predict trends, we fitted an autoregressive Bayesian log-linear Poisson model to the observed data in 1991-2012. This model allows better predictions in situations where other models may fail ${ }^{20}$ and gives more weight to data from recent periods, especially when changing trends arise through the study period. ${ }^{21}$ In this line, the temporal trend was modelled through a random walk (RW). We assessed the performance of the model comparing an RW of order 1, which assumes constant rate of changes, with an RW of order 2 , which is a moving average that changes in time and allows for smoothing of the trend. ${ }^{21}$ We found that the model with RW of order 2 showed less variability in the withinsample prediction of the observed cigarettes per capita in 1991-2012, and then the RW of order 2 assumption was used (see online supplementary figure S1). Once the model was fitted, we predicted the cigarette consumption for the period 2013-2020, based on the time trend estimated with this Bayesian model.

\section{RESULTS}

The daily consumption per capita of manufactured cigarettes decreased from 7.6 units in 1991 to 3.8 units in 2012, with an average APC of -3.0 (figure 1). The daily consumption per capita of RYO cigarettes in the same period increased according to the scenario considered, from 0.07 to 0.92 units of $0.5 \mathrm{~g}$, from 0.04 to 0.58 units of $0.8 \mathrm{~g}$ and from 0.03 to 0.46 units of $1 \mathrm{~g}$ (average APC: 14.1). This represents an increase in the proportion of RYO cigarettes from $0.9 \%$ in 1991 to $19.6 \%$ in 2012 of overall cigarettes per capita, considering rolled units of $0.5 \mathrm{~g}$ (from $0.5 \%$ to $13.3 \%$ and from $0.4 \%$ to

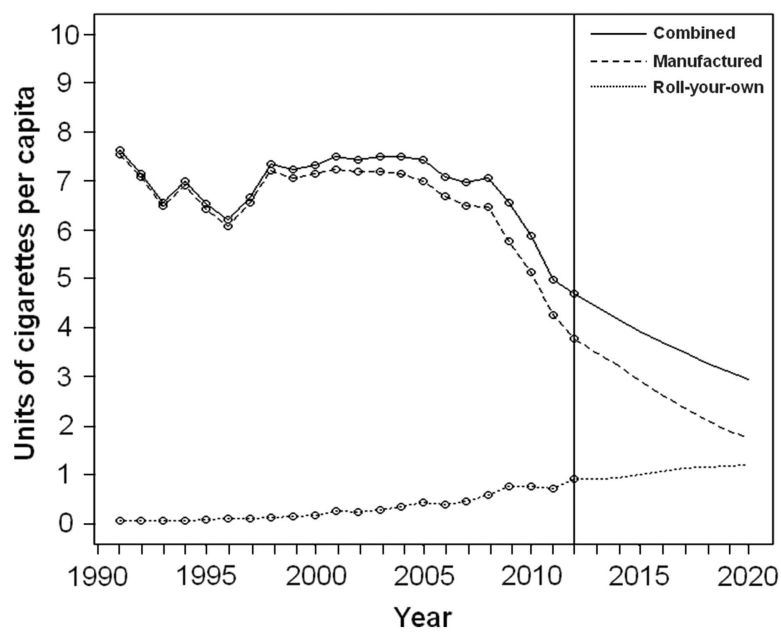

Figure 1 Daily cigarette consumption per capita (units of factory-made and roll-your-own cigarettes) in Spain during 1991-2012 and predictions for the years 2013-2020. 
$10.8 \%$ considering RYO cigarettes of 0.8 and $1 \mathrm{~g}$, respectively). Overall, daily consumption per capita (manufactured plus RYO cigarettes) decreased from 7.6 to 4.7 units (average APC: -2.1 ), from 7.6 to 4.4 units (average APC: -2.4 ) and from 7.6 to 4.2 units (average APC: -2.5), depending on the weight of the RYO cigarettes considered.

Joinpoint analyses (table 1) indicated a decrease in the consumption of manufactured cigarettes at the beginning of the period (1991-1996), then a period of non-significant rising during 1997-2001, and then a significant downward trend in 2002-2008, which accelerated afterwards in 2009-2012 (APC of -12.6). When we considered only RYO cigarettes, we observed a continuous significant increasing trend of $14.1 \%$ for the whole study period (1991-2012).

Figure 1 shows the trends in daily consumption of units of manufactured and RYO cigarettes, as well as the projections up to 2020. For that year, differences between the consumption of both types of cigarettes taken together (solid line) and the consumption of manufactured cigarettes only (dashed line) reach a $36 \%$ increase compared to that observed at the end of the observed period in 2012. By 2020, projections indicate a daily consumption per capita of 1.75 units of manufactured cigarettes and 1.25 units of RYO cigarettes, the latter representing $41.6 \%$ of overall cigarettes per capita projected by that year.

\section{DISCUSSION}

Besides a decrease in daily consumption per capita of manufactured cigarettes, we observed an increase in the consumption of RYO cigarettes, thus indicating a shift from one form to another. We found an increasing contribution of the RYO cigarettes to the overall cigarette consumption per capita during 1991-2012. These changes have to be taken into account in future tobacco control policies. They represented $0.9 \%$ in 1991 and $19.6 \%$ in 2012 of overall cigarette consumption per capita, when considering RYO units of $0.5 \mathrm{~g}$. This trend has also been observed in other developed countries, ${ }^{22-24}$ including younger populations. ${ }^{25}$ Although the global trend of daily use of cigarettes per capita is decreasing, the increasing trend of use of RYO cigarettes is a matter of great concern, and our projections indicate that it will continue in the future at a higher rate, with an estimated proportion of $41.7 \%$ of overall cigarettes per capita by the year 2020 .

Article 6 of the FCTC urges the parties to adopt price and tax measures for all tobacco products. ${ }^{2}$ In Spain, several tax reforms have accompanied the implementation of more restrictive tobacco regulations, but they have been mainly applied to manufactured cigarettes. In recent years, the prices of these products have been remarkably different, with rolling tobacco costing about $50 \%$ less than manufactured cigarettes until 2009, when a small tax was introduced. However, an increase in the market share of rolling tobacco has been observed, from $1.6 \%$ to $5.1 \%$ of sales from 2005 to 2011 . $^{13}$

The decrease in sales of manufactured cigarettes is possibly in part a collateral effect of the Spanish smokefree legislation of 2010, reflecting less smoking by adult smokers. The current economic crisis could also have contributed to make some smokers shift from manufactured to RYO cigarettes, especially younger smokers. This shift should be explored in depth in order to develop prevention strategies, especially among young people. A New Zealand study found that the reasons referred by smokers for this shift are, in order of importance, that RYO cigarettes are cheaper, taste better, are more satisfying, reduce the amount smoked and have less harmful effects. ${ }^{26}$ With a more detailed knowledge of this shift by population strata, more appropriate strategies may be planned to tackle rolling tobacco consumption and encourage cessation-among them, awareness campaigns and better information to the population on the health effects of rolling tobacco, with an emphasis on youth and socioeconomic deprived areas.

Some limitations of our investigation deserve consideration. First, we estimated the cigarette consumption per capita by means of the information available on product sales. This information provides a crude estimation of the population's consumption, as it does not distinguish between sales to the Spanish population and sales to the tourists, a common situation especially in the nation's border and coastal provinces. On the other hand, official sales do not include smuggling, and therefore a

Table 1 Joinpoint analyses of daily cigarette consumption per capita by adult population $\geq 16$ years old in Spain (manufactured cigarettes, roll-your-own cigarettes and both type of cigarettes) over the period 1991-2012 and the corresponding annual per cent of change (and their $95 \% \mathrm{Cls}$ )

\begin{tabular}{lllll}
\hline & Trend 1 & Trend 2 & Trend 3 & Trend 4 \\
\hline Period & $1991-1996$ & $1997-2001$ & $2002-2008$ & $2009-2012$ \\
Manufactured cigarettes & $-2.9(-5.3 \text { to }-0.6)^{*}$ & $3.3(-0.2$ to 6.9$)$ & $-1.9(-3.7 \text { to }-0.1)^{*}$ & $-12.6(-16.2 \text { to }-8.9)^{*}$ \\
Period & $1991-1996$ & $1997-2001$ & $2002-2008$ & $2009-2012$ \\
Combined cigarettes & $-2.8(-5.3 \text { to }-0.3)^{*}$ & $3.6(-0.1$ to 7.3$)$ & $-1.1(-2.9$ to 0.8) & $-9.8(-13.4 \text { to }-6.8)^{*}$ \\
Period & $1991-2012$ & - & - & - \\
Roll-your-own cigarettes & $14.1(13.1 \text { to 15.2 })^{*}$ & - & - & - \\
\hline${ }^{*}$ Statistically significant $(\mathrm{p}<0.05)$. & & &
\end{tabular}


variable portion of the consumption is not being considered. However, smuggling had hugely decreased in the past decades ${ }^{27}$ and in a European survey conducted in 2010 only $3.4 \%$ of Spanish smokers self-reported purchase from an illicit source. ${ }^{28}$ Second, information on tobacco sales is heterogeneous. In the case of manufactured cigarettes, sales were registered in 'packs' in the first years (until 2005, packs of 10 and 19 cigarettes existed, although they represented a very small portion of the volume share). The available information on rolling tobacco is more heterogeneous, because the registries on sales during the first years included units of the product and no specification on their weights was provided. Fortunately, information on units of the product and the corresponding kilograms was available for the year 2008, allowing us to obtain some estimations. Third, the amount of tobacco in a RYO cigarette is variable, and this contributes to an imprecise estimation of the number of cigarettes. Some reports have used conversion factors between 0.6 and $0.9 \mathrm{~g}$ per cigarette, ${ }^{5} 1322{ }^{24}$ and according to the Pricing Policy And Control of Tobacco in Europe (PPACTE) project in 2010, the median weight of RYO cigarettes ranged between 0.48 and $1.15 \mathrm{~g}^{29}$ In our study, we used three different options $(0.5,0.8$ and $1 \mathrm{~g})$. Fourth, pipe tobacco can be also used to make RYO cigarettes, so their unitary estimations may be slightly underestimated, although less than $1 \%$ of the Spanish population smoked pipes. ${ }^{30}$ Despite this, our analysis allowed us to provide an estimation of tobacco sales (and tobacco consumption) at a national level and, more importantly, allowed us to compare the consumption of manufactured and RYO cigarettes. We have used a well-established timeseries methodology to assess cigarette consumption over time. The statistical modelling through Bayesian autoregressive assumption appears a useful method to assess the long-run relationship between manufactured and RYO cigarettes. Moreover, the net estimations of manufactured and RYO cigarettes according to the constraints of the Bayesian model were similar to the data observed per year (see online supplementary table $\mathrm{S} 1$ ).

In conclusion, although the sales of manufactured cigarettes are decreasing as observed in the past years in Spain, use of RYO cigarettes is progressively increasing. Rolling tobacco sales will continue to increase in the next years, partly due to a shift in the consumption from manufactured to RYO cigarettes. More attention should be paid to this and other alternative tobacco products in order to hinder its access, especially to young people. More concrete strategies, such as higher taxation and information on their health effects, are key strategies to be developed, with emphasis on specific populations.

\footnotetext{
Author affiliations

${ }^{1}$ Tobacco Control Unit, Cancer Prevention and Control Programme, Catalan Institute of Oncology-ICO, L'Hospitalet de Llobregat, Barcelona, Spain ${ }^{2}$ Cancer Control and Prevention Group, Bellvitge Biomedical Research Institute-IDIBELL, L'Hospitalet de Llobregat, Barcelona, Spain
}

${ }^{3}$ Department of Clinical Sciences, School of Medicine, Universitat de Barcelona, Barcelona, Spain

${ }^{4}$ Biostatistics Unit, Department of Basic Sciences, Universitat Internacional de Catalunya, Sant Cugat del Vallès, Barcelona, Spain

${ }^{5}$ Public Health Advocacy Institute, Northeastern University, Boston,

Massachusetts, USA

${ }^{6}$ Cancer Registry of Catalonia, Plan for Oncology of the Catalan Government, L'Hospitalet de Llobregat, Barcelona, Spain

${ }^{7}$ Public Health Agency of Barcelona, Barcelona, Spain

${ }^{8}$ Biomedical Research Networking Centre of Public Health and EpidemiologyCIBERESP, Barcelona, Spain

${ }^{9}$ Biomedical Research Institute Sant Pau, Barcelona, Spain

${ }^{10}$ Department of Social and Behavioral Sciences, Center for Global Tobacco Control, Harvard School of Public Health, Boston, Massachusetts, USA

Contributors JMMS and EF conceived the study. MF, RC and JMMS prepared the database and conducted the analyses. All the authors contributed substantially to the interpretation of the data. MF drafted the first version of the manuscript; all the authors contributed to its subsequent versions and approved the final version. EF is the guarantor.

Funding This work was supported by the Instituto de Salud Carlos III, Government of Spain (RTICC RD12/0036/0053 and BAE 14/00014) and the Ministry of Universities and Research, Government of Catalonia (grant 2009SGR192).

\section{Competing interests None.}

Provenance and peer review Not commissioned; externally peer reviewed.

Data sharing statement No additional data are available.

Open Access This is an Open Access article distributed in accordance with the Creative Commons Attribution Non Commercial (CC BY-NC 4.0) license, which permits others to distribute, remix, adapt, build upon this work noncommercially, and license their derivative works on different terms, provided the original work is properly cited and the use is non-commercial. See: http:// creativecommons.org/licenses/by-nc/4.0/

\section{REFERENCES}

1. World Health Organization. WHO Report on the Global Tobacco Epidemic, 2008: the MPOWER package. Geneva: WHO Press, 2008. http://www.who.int/tobacco/mpower/en/ (accessed Aug 2014).

2. World Health Organization. WHO framework convention in tobacco control. Geneva: World Health Organization, 2003. http://www.who. int/fctc/text download/en/index.html (accessed Aug 2014).

3. Eriksen MP, Mackay JL, Ross H. The tobacco atlas. Atlanta, GA: American Cancer Society, Inc, 2012. http://www.TobaccoAtlas.org (accessed Aug 2014).

4. Prignot JJ, Sasco AJ, Poulet E, et al. Alternative forms of tobacco use. Int J Tuberc Lung Dis 2008;12:718-27.

5. Centers for Disease Control and Prevention. Current tobacco use among middle and high school students-United States, 2011. Morb Mortal Wkly Rep 2012;61:581-5.

6. Villalbí JR, Suelves JM, García-Continente X, et al. [Changes in smoking prevalence among adolescents in Spain]. Aten Primaria 2012:44:36-42.

7. U.S. Department of Health and Human Services. Preventing tobacco use among youth and young adults: a report of the Surgeon General. Atlanta: U.S. Department of Health and Human Services, Centers for Disease Control and Prevention, Office on Smoking and Health, 2012.

8. Young D, Wilson N, Borland R, et al. Prevalence, correlates of, and reasons for using roll-your-own tobacco in a high $\mathrm{RYO}$ use country: Findings from the ITC New Zealand Survey. Nicotine Tob Res 2010;12:1089-98.

9. O'Connor RJ, McNeill A, Borland R, et al. Smokers' beliefs about the relative safety of other tobacco products: findings from the ITC collaboration. Nicotine Tob Res 2007;9:1033-42.

10. Shahab L, West R, McNeill A. A comparison of exposure to carcinogens among roll-your-own and factory-made cigarette smokers. Addict Biol 2009;14:315-20.

11. Castaño Calduch T, Hebert Jiménez C, Campo, et al. [Fine-cut tobacco: a priority for public health and consumer advocacy]. Gac Sanit 2012;26:267-9.

12. Darrall KG, Figgins JA. Roll-your-own smoke yields: theoretical and practical aspects. Tob Control 1998;7:168-75. 
13. López-Nicolás Á, Cobacho MB, Fernández E. The Spanish tobacco tax loopholes and their consequences. Tob Control 2013;22:e21-4.

14. Ministerio de Hacienda y Administraciones Públicas. Comisionado para el Mercado de Tabacos. Tobacco market statistics and indicators. http://www.cmtabacos.es/wwwcmt/paginas/EN/ mercadoEstadisticas.tmpl (accessed Aug 2014).

15. Ministerio de Hacienda y Administraciones Públicas. Comisionado para el Mercado de Tabacos. Tobacco market statistics and indicators. Data on sales of packs of 20 cigarettes and bags/cans of rolling tobacco for 2007-2008. http://www.cmtabacos.es/wwwcmt/ verEstadistica.php?a=2008\&f=2008_comun-u (accessed Aug 2014).

16. Ministerio de Hacienda y Administraciones Públicas. Comisionado para el Mercado de Tabacos. Tobacco market statistics and indicators. Data on sales of packs of 20 cigarettes and kilos of rolling tobacco for 2008-2009. http://www.cmtabacos.es/wwwcmt/ verEstadistica.php?a=2009\&f=2009_comun-u (accessed Aug 2014).

17. Instituto Nacional de Estadística. Population figures and Demographic Censuses. http://www.ine.es/en/inebmenu/mnu cifraspob_en.htm (accessed Aug 2014).

18. Gallus S, Tramacere I, Boffetta P, et al. Temporal changes of under-reporting of cigarette consumption in population-based studies. Tob Control 2011;20:34-9.

19. Martínez-Sánchez JM, Fu M, Gallus S, et al. [Variability in cigarette consumption according to the data source in Spain (1993-2009)]. Gac Sanit 2013;27:61-3.

20. Kim HJ, Fay MP, Feuer EJ, et al. Permutation tests for joinpoint regression with applications to cancer rates. Stat Med 2000;19:335-1 (erratum in Stat Med 2001;20:655).
21. Clèries $\mathrm{R}$, Martínez $\mathrm{JM}$, Moreno $\mathrm{V}$, et al. Predicting the change in breast cancer deaths in Spain by 2019: a Bayesian approach. Epidemiology 2013;24:454-60.

22. Connolly GN, Alpert HR. Trends in the use of cigarettes and other tobacco products, 2000-2007. JAMA 2008;299:2629-30.

23. Young D, Yong HH, Borland R, et al. Trends in roll-your-own smoking: findings from the ITC Four-Country Survey (2002-2008). $J$ Environ Public Health 2012;2012:406283.

24. Gallus S, Lugo A, Colombo P, et al. Smoking prevalence in Italy 2011 and 2012, with a focus on hand-rolled cigarettes. Prev Med 2013;56:314-18.

25. Raisamo SU. Trends in roll-your-own tobacco use among adolescents in Finland, 1981-2009. Prev Med 2011;53:431-2.

26. Wilson N, Young D, Weerasekera D, et al. The importance of tobacco prices to roll-your-own (RYO) smokers (national survey data): higher tax needed on RYO. N Z Med J 2009;122: $92-6$.

27. Joossens L, Raw M. Progress in combating cigarette smuggling: controlling the supply chain. Tob Control 2008;17:399-404.

28. Joossens L, Lugo A, La Vecchia C, et al. Illicit cigarettes and hand-rolled tobacco in 18 European countries: a cross-sectional survey. Tob Control 2014;23:e17-23.

29. Gallus S, Lugo A, Ghislandi S, et al. Roll-your-own cigarettes in Europe: use, weight and implications for fiscal policies. Eur J Cancer Prev 2014;23:186-92.

30. Bilal U, Fernández $\mathrm{E}$, Beltran $\mathrm{P}$, et al. Validation of a method for reconstructing historical rates of smoking prevalence. $A m \mathrm{~J}$ Epidemiol 2014;179:15-19. 